HORTSCIENCE 27(5):438-440. 1992.

\title{
Relationship between Starchy versus Sugary Endosperm and Head Smut Susceptibility of Corn Seedlings
}

James R. Baggett ${ }^{1}$ and Janice Tibbs ${ }^{2}$

Department of Horticulture, Oregon State University, 2042 Cordley Hall, Corvallis, OR 97331-2911

Additional index words. Zea mays, sweet corn breeding, Sphacelotheca reiliana

Abstract. Incidence of head smut [Sphacelotheca reiliana (Kuhn) Clinton] in $\mathbf{F}_{3}$ corn (Zea mays L.) families derived from homozygous starchy $(\mathrm{Su}) \mathrm{F}_{2}$ ears was less than that observed in starchy or sugary $(\mathrm{su})$ families derived from segregating ears or sugary families derived from homozygous sugary ears. This difference was observed at high levels of disease incidence resulting from clipping seedlings and at a lower disease incidence in unclipped plants. Differences in seedling vigor and earliness of starchy and sugary families and differences related to homozygous and heterozygous sources suggest that seedling vigor may be involved in the observed differences in head smut susceptibility.

Sphacelotheca reiliana, the incitant of head smut disease, infects corn seedlings mostly before about the sixth leaf stage (V3 to V4 stages of Ritchie et al., 1989) by means of germinating spores in the soil (H.S. Fenwick, personal communication). Genetic susceptibility is characterized by differences in potential for seedling infection and is expressed as differences in disease incidence. The principal symptoms in infected plants of relatively resistant or susceptible corn lines are the same and consist of production of massive sori replacing the ear and sometimes the tassel, along with a degree of plant stunting (Baggett and Kean, 1989; Foster and Frederiksen, 1977; Halisky, 1963; Maytac and Windels, 1984).

In many years of testing commercial sweet corn (sugary, su) $\mathrm{F}_{1}$ hybrids and inbred lines, using furrow inoculation (Baggett and Koepsell, 1983), infection incidence has ranged from $0 \%$ to $100 \%$. Potential for infection was shown to be inherited in a quantitative, mostly additive manner, with resistance showing a degree of dominance over susceptibility when infection levels were low.

Received for publication 15 Apr. 1991. Accented for publication 2 Dec. 1991. Oregon Agricultural Experiment Station Technical Paper no. 9558. The cost of publishing this paper was defrayed in part by the payment of page charges. Under postal regulations, this paper therefore must be hereby marked advertisement solely to indicate this fact. ${ }^{1}$ Professor.

${ }^{2}$ Former Graduate Research Assistant.
In $\mathrm{F}_{2}$ and backcross populations, where starchy $(\mathrm{Su})$ and sugary (su) segregates were planted in separate adjacent plots, plants with sugary endosperm had significantly higher head smut incidence than plants with starchy endosperm (Ali and Baggett, 1990). No evidence was available to explain the reduced infection incidence in starchy plants, but it was assumed to be related to seedling vigor. The objective of the present study was to further measure the effect of starchy vs. sugary endosperm from homozygous and heterozygous sources, and to determine possible relationships between disease incidence, starchy/sugary endosperm, and some other characteristics, including seedling vigor.

Populations were obtained by crossing dent corn inbred line Nebraska 6 (N6) with sugary inbred lines SD1 and SM7. SD1 was derived by selfing the commercial hybrid 'Sugar Daddy' (Ferry Morse Seed Co., Stockton, Calif.). SM7 was derived from a breeding line provided by W. Crookham Seed Co. (Caldwell, Idaho). N6 is highly resistant to head smut, rarely being infected even under high disease pressure. Infection incidence in highly susceptible SD1 and SM7 may reach $\geq 90 \%$. $\mathrm{F}_{3}$ families for study were obtained by self-pollinating $80 \mathrm{~F}_{2}$ plants from each of the four reciprocal crosses. To ensure that enough homozygous sugary $(s u / s u)$ families were obtained, starchy and sugary $F_{2}$ seeds were sorted and planted separately. For each reciprocal cross, 40 homozygous sugary ears were obtained, and the remaining 40 ears per cross included starchy ears from homozy- 
Table 1. Effect of starchy vs. sugary endosperm and clipping of seedlings on incidence of head smut in corn $\mathrm{F}_{3}$ families.

\begin{tabular}{|c|c|c|c|c|c|}
\hline & & \multicolumn{4}{|c|}{ Cross $^{z}$} \\
\hline \multirow{2}{*}{\multicolumn{2}{|c|}{ Endosperm }} & \multicolumn{2}{|c|}{ N6 x SD1 } & \multicolumn{2}{|c|}{ N6 x SM7 } \\
\hline & & & Infected ${ }^{w}$ & & Infected \\
\hline Type & Source $^{y}$ & $\mathrm{~N}^{\mathrm{x}}$ & $(\%)$ & $\mathrm{N}$ & $(\%)$ \\
\hline \multicolumn{6}{|l|}{ Clipped } \\
\hline \multirow[t]{2}{*}{ Starchy } & Homozygous & 60 & $21.4 \mathrm{~A}$ & 50 & $38.1 \mathrm{~A}$ \\
\hline & Heterozygous & 100 & 39.4 B & 110 & $43.8 \mathrm{AB}$ \\
\hline \multirow{2}{*}{ Sugary } & Heterozygous & 100 & $47.6 \mathrm{C}$ & 110 & $49.8 \mathrm{~B}$ \\
\hline & Homozygous & 160 & $43.0 \mathrm{BC}$ & 160 & $46.5 \mathrm{~B}$ \\
\hline \multicolumn{6}{|l|}{ Unclipped } \\
\hline \multirow[t]{2}{*}{ Starchy } & Homozygous & 60 & $8.4 \mathrm{~A}$ & 50 & $11.1 \mathrm{~A}$ \\
\hline & Heterozygous & 100 & $15.5 \mathrm{~B}$ & 110 & $15.2 \mathrm{AB}$ \\
\hline \multirow[t]{2}{*}{ Sugary } & Heterozygous & 100 & $24.5 \mathrm{C}$ & 110 & $19.4 \mathrm{BC}$ \\
\hline & Homozygous & 160 & $19.8 \mathrm{C}$ & 160 & $21.8 \mathrm{C}$ \\
\hline Starchy & All plots & 320 & $22.7 \mathrm{~A}$ & 320 & $28.0 \mathrm{~A}$ \\
\hline Sugary & All plots & 520 & $33.2 \mathrm{~B}$ & 540 & $34.3 \mathrm{~B}$ \\
\hline Clipped & All plots & 420 & $40.1 \mathrm{~B}$ & 430 & $45.7 \mathrm{~B}$ \\
\hline Unclipped & All plots & 420 & $18.3 \mathrm{~A}$ & 430 & $18.3 \mathrm{~A}$ \\
\hline
\end{tabular}

${ }^{2}$ Reciprocal crosses have been combined.

${ }^{y}$ Genotype of the $F_{2}$ ear from which the planted $F_{3}$ seeds were obtained.

${ }^{\times} \mathbf{N}=$ number of plots from which the means were derived; number of families represented was onehalf the number shown for the clipped or unclipped plots; each family was replicated two times in clipped and two times in unclipped treatments.

"Means bearing the same letter within a cross-clipping combination, between overall starchy-sugary means, and between overall clipping means were not different at $P=0.05$ using Student's $t$ test. Arcsin-transformed values were used to determine mean separations.

Table 2. Relation of seedling height, earliness, and mature plant height with endosperm type and source in corn $\mathrm{F}_{3}$ families. ${ }^{\mathrm{z}}$

\begin{tabular}{|c|c|c|c|c|c|c|c|c|c|}
\hline \multirow{2}{*}{\multicolumn{2}{|c|}{ Endosperm }} & \multicolumn{4}{|c|}{ Seedling $\mathrm{ht}^{\mathrm{y}}$} & \multicolumn{2}{|c|}{ Earliness $^{x}$} & \multicolumn{2}{|c|}{ Mature $h^{w}{ }^{w}$} \\
\hline & & \multicolumn{2}{|c|}{ N6 $\times$ SD1 } & \multicolumn{2}{|c|}{$\mathrm{N} 6 \times \mathrm{SM} 7$} & \multirow{2}{*}{$\begin{array}{c}\text { N6 } \times \text { SD1 } \\
\text { (days) }\end{array}$} & \multirow{2}{*}{$\begin{array}{c}\text { N6 } \times \text { SM7 } \\
\text { (days) }\end{array}$} & \multirow{2}{*}{$\begin{array}{l}\text { N6 } \times \text { SD1 } \\
(\mathrm{cm})\end{array}$} & \multirow{2}{*}{$\begin{array}{c}\text { N6 } \times \text { SM7 } \\
(\mathrm{cm})\end{array}$} \\
\hline Type & Sourcev $^{v}$ & $N$ & $\mathrm{~cm}$ & $\mathbf{N}$ & $\mathrm{cm}$ & & & & \\
\hline archy & Homo & 120 & $24.8 \mathrm{C}$ & 100 & $.9 \mathrm{~B}$ & $75.0 \mathrm{BC}$ & $72.7 \mathrm{~B}$ & $82.1 \mathrm{~A}$ & $80.0 \mathrm{~B}$ \\
\hline Starchy & Heter & 200 & $25.6 \mathrm{D}$ & 220 & 25 & & & & \\
\hline Sugary & Heterozygous & 200 & $21.8 \mathrm{~A}$ & 220 & & & & & \\
\hline Sugary & Hom & 320 & $22.1 \mathrm{~A}$ & 320 & 2 & 75. & & 83. & 0 \\
\hline Starchy & All s & 320 & $25.3 \mathrm{~B}$ & 320 & 25 . & 74. & 71 & 83.7 & 79 \\
\hline Sugary & All sources & 520 & 22.0 & 540 & & 75 . & $73.4 \mathrm{~B}$ & 84.0 & $78.9 \mathrm{~A}$ \\
\hline
\end{tabular}

${ }^{2}$ Reciprocal crosses combined.

yPlot average of height of seedlings to tip of longest leaf 23 to 26 days after seeding; one replication of each family measured each of 4 days. Means bearing the same letter within a column (starchy vs. sugary, all sources compared separately) did not differ at $P=0.05$, determined by Student's $t$ test. N $=$ number of plots measured to derive means shown.

${ }^{x}$ Earliness expressed as days from seeding to $50 \%$ silk emergence.

wMature plant height measured to top of tassel after all growth had ceased.

${ }^{\vee}$ Genotype of the $F_{2}$ plant from which families were derived.

gous starchy $\mathrm{F}_{2}$ plants and segregating ears from heterozygous $(\mathrm{Su} / \mathrm{su}) \mathrm{F}_{2}$ plants. Starchy and sugary $\mathrm{F}_{3}$ kernels on the segregating $\mathrm{F}_{2}$ ears were sorted into separate lots that were planted together as a single plot in the head smut test and observation plots described below. For the two crosses and reciprocals combined, $425 \mathrm{~F}_{3}$ families were studied. The number of families studied for each endosperm type is shown in Table 1.

The following season, seed of each $\mathrm{F}_{3}$ family was divided into eight lots. Four replications of each $\mathrm{F}_{3}$ family were planted in a head smut-infested field with inoculum consisting of teliospores mixed with vermiculite applied in the seed furrow as described by Baggett and Koepsell (1983). Plots were arranged in a randomized complete-block design except that starchy sublines were planted adjacent to sugary sublines derived from the same segregating ear. Each 3-m plot contained $\approx 10$ plants in rows $90 \mathrm{~cm}$ apart.
Seedlings of two replications in the inoculated field were clipped at ground level at the V2 to V3 stage (four to five visible leaves), a treatment known to substantially increase the incidence of head smut (Ali and Baggett, 1986). General cultural practices were similar to those used in commercial sweet corn production in the area. The presence of infection, expressed as sori on an ear or tassel, was determined at crop maturity.

Four replications were planted in a similar arrangement in a head smut-free field on the same research farm. Characters measured were seedling height 23 to 26 days after planting (one replication measured on each of these 4 days); earliness, determined by date when silks had emerged on $50 \%$ of the plants; and mature plant height to the top of the tassel. Endosperm type (starchy or sugary) was predetermined by sorting ears or kernels as previously described.

The percentage of clipped seedlings in- fected, averaged over the two crosses, was more than double that of unclipped seedlings, providing two distinct levels of disease incidence in the study. The effect of clipping was highly significant in each cross (Table 1).

Overall (with sources of starchy and sugary seeds not considered), disease incidence was significantly higher in sugary plants than in starchy plants (Table 1). In N6 × SD1, there were also significant differences in percentage infected between starchy families derived from homozygous ears and those derived from segregating ears. This difference was marked in clipped and unclipped plots and was larger than the consistent (but not always significant) differences between starchy and segregating ears and both sugary categories. In N6 $\times$ SM7 progeny, all differences due to endosperm type followed a similar pattern, but the difference between starchy sources, and some other comparisons, were nonsignificant at $P=0.05$.

Because starchy corn often is observed to have stronger germination and seedling vigor than sugary corn, seedling vigor expressed as height, earliness, and mature plant height were measured to determine whether these factors would explain the tendency of starchy corn to be less susceptible to head smut infection. Starchy seedlings were significantly taller than sugary (Table 2), which supported the hypothesis that increased seedling vigor was associated with less infection. However, the small differences in seedling height between starchy and heterozygous and homozygous sources failed to support, and even contradicted, this hypothesis since seedlings from the homozygous source were slightly shorter and had lower disease incidence. Seedling height of the sugary plants from the two sources was nearly identical.

Sugary and starchy plants from heterozygous sources were earlier to flower than counterparts from homozygous sources, and, overall, starchy corn was earlier than sugary corn. Differences in mature plant height were small and there was no obvious pattern.

This study confirmed previous observations that starchy corn plants were less susceptible to head smut infection than sugary plants. While it seems likely to us that differences in susceptibility between sugary and starchy plants are related to differences in seedling vigor associated with the presence or absence of the $\mathrm{Su}$ allele, differences between starchy lines from homozygous and heterozygous sources are more difficult to explain. It is possible that the differences observed were accidental and resulted from general diverse segregation occurring within the $\mathrm{F}_{3}$ families. However, this difference might also be related in some way to greater heterosis in starchy plants derived from heterozygous sources, since we would expect two-thirds of these starchy plants to be heterozygous for the $S u$ factor. While we favor the hypothesis that reduced disease incidence, whether associated with seedling vigor or not, is a pleiotropic effect of the Su allele (when compared with the $s u$ allele), we cannot exclude the possibility that increased vigor 
and/or resistance may be conditioned by factors linked to the $S u$ gene.

That lower seedling vigor is associated with higher susceptibility is suggested by the conspicuous increase in disease incidence caused by seedling clipping. The effect of clipping on infection percentage is apparently related to a setback of seedlings that, while considered to be temporary, can be easily observed for several weeks.

It should be noted that we have tested very resistant sugary hybrids and inbreds and very susceptible starchy accessions. Thus, differences in susceptibility described here represent tendencies only and do not preclude the possibility of breeding head smut-resistant sugary corn cultivars.

\section{Literature Cited}

Ali, A. and J.R. Baggett. 1986. Predisposition of corn plants to the head smut disease by clipping for the selection of resistant genotypes. J. Agr. Res. (Pakistan) 24:223-227.

Ali, A. and J.R. Baggett. 1990. Inheritance of resistance to head smut disease in corn. J. Amer. Soc. Hort. Sci. 115(4):668-672.

Baggett, J.R. and P.A. Koepsell. 1983. Field inoculation of sweet corn with the head smut pathogen (Sphacelotheca reiliana). HortScience 18(1):67-68.

Baggett, J.R. and D. Kean. 1989. Reduction of plant height by head smut infection in sweet corn cultivars. HortScience 24(3):497-499.

Foster, J.H. and R.A. Frederiksen. 1977. Symptoms of head smut in maize seedlings and evaluations of hybrids and inbreds. Texas Agr. Expt. Sta. PR-433:1-4.

Halisky, P.M. 1963. Head smut of sorghum, sudan grass, and corn, caused by Sphacelotheca reiliana (Kuhn) Clint. Hilgardia 34:287-304.

Matyac, C.A. and C.E. Windels. 1984. Smut expression and resistance of corn to Sphacelotheca reiliana in Minnesota. Plant Dis. 68:880884.

Ritchie, S.W., J.J. Hanway, and S.J. Lupkes. 1989. How a corn plant develops. Spec. Rpt. no. 48, Iowa State Univ. Sci. and Technol. Coop. Ext. Serv. 